\title{
HOW COULD BOLTZMANN HAVE INSPIRED THE EARLY WITTGENSTEIN?
}

Keywords: Wittgenstein, Boltzmann, Fleck

Słowa kluczowe: Wittgenstein, Boltzmann, Fleck

Strange ontological theses open up Wittgenstein's Tractatus logico-philosophicus. The world, we read, divides into states of affairs, each of which may or may not occur regardless of the occurrence of any other states of affairs (Wittgenstein, 1961a, 1.21 \& 2). Each state of affairs is an impermanent combination of objects that are permanent $(2.01 \& 2.027 \& 2.0271)$.

This so-called logical atomism is highly counterintuitive, not least because the text lacks examples of objects and states of affairs. More importantly, in the scientific pictures of the world - from the beginning of the 20th

* Wojciech Sady_philosopher of science and historian of ideas. In 2020 he published the book The Structure of the Relativistic and Quantum Revolution in Physics (in Polish, English translation in progress). He is author of the entry on Ludwik Fleck in The Stanford Encyclopedia of Philosophy.

Address for correspondence: Kremerowska 14/6, 31-130 Krakow, Poland. E-mail: wojciech.sady@gmail.com. 
century or the present one - there are no parts of the world that can be the case or not the case while everything else remains the same. Nor does the image of the world of common sense know such independent facts.

Some (pseudo)arguments in favor of such a formal ontology appear in the sections of the book on what form our ordinary propositions would take after a complete logical analysis of them. We will not find a single example of analysis there, which does not prevent Wittgenstein from saying: "It is obvious that the analysis of propositions must bring us to elementary propositions which consist of names in immediate combination" (4.221). Names denote objects, and in an elementary proposition they are connected just as objects are connected in a pictured state of affairs. The counterpart of the ontological theses of logical atomism is now the thesis that elementary propositions are logically independent: "It is a sign of a proposition's being elementary that there can be no elementary proposition contradicting it" (4.211).

In science, propositions describing a certain situation are used together with the laws of nature to infer propositions that e.g., a different situation will occur in the future. Wittgenstein considers this to be a mistake: "The whole modern conception of the world is founded on the illusion that the so-called laws of nature are the explanations of natural phenomena" $(6,371)$. Earlier, he stated: "The exploration of logic means the exploration of everything that is subject to law. And outside logic everything is accidental" (6.3). "What is thinkable is possible too" (3.02). We read in the commentary to 6.3: "Mechanics determines one form of description of the world" (6.341), "the possibility of describing the world by means of Newtonian mechanics tells us nothing about the world" (6.342).

The question arises whether Tractatus logico-philosophicus is not only a metaphysical but also anti-scientific book? Or maybe it is possible to indicate in physics at the turn of 20 th century a research program that could suggest such ontological theses?

\section{2}

Who inspired the early Wittgenstein, and how? It is usually claimed that the logical parts of the Tractatus are a critical development of Frege and Russell's ideas. And that the remarks about the mystical were influenced by Schopenhauer, Weininger, Kraus and others. But Wittgenstein in 1931 
gave the following list of authors who influenced him: "Boltzmann, Hertz, Schopenhauer, Frege, Russell, Kraus, Loos, Weininger, Spengler, Sraffa" (Wittgenstein, 1980, p. 19). Here the question arises: does Ludwig Boltzmann open this list by accident? And even if by accident, why is he in this group?

The aforementioned list has been widely known for forty years, but typical commentators of Tractatus are of little interest to the possible influence of Boltzmann on the early Wittgenstein. Boltzmann is not even mentioned - to give some representative examples - neither in the entry on Wittgenstein's logical atomism in The Stanford Encyclopedia of Philosophy (Proops, 2017), nor in the nearly 400-page introduction to Tractatus (Morris, 2008), nor in The New Wittgenstein (Crary, Read, 2000). There is nothing about Boltzmann in (Sluga, Stern, 2018). In biographical sections, some books mention that the 17-year-old Wittgenstein intended to study physics under Boltzmann, but Boltzmann committed suicide. I have found only a few articles in English on the possible influence of Boltzmann on the ideas of Tractatus (Blackmore, 1983, 1999; Harré, 2001; Montibeller, 2016; Nordmann, 2002; Preston, 2016; Stern, 2002; Sterrett, 2006, ch. 6; Visser, 1999; Wilson, 1989). None of them contain a hypothesis similar to the one I formulate below.

John M. Preston considers the possible influences of Hertz and Boltzmann on the early Wittgenstein, especially on his conception of the aims and methods of philosophy, and concludes his article with the statement: "We can have little certainty about the ways in which [Wittgenstein] was influenced by Hertz and Boltzmann, but his relationship to their ideas was probably one of creative appropriation" (Preston, 2016, p. 121).

\section{3}

Boltzmann (1866) tried to derive the second law of thermodynamics from the laws of mechanics, using the law of conservation of energy and the kinetic theory of heat. Then he read an article in which James Clerk Maxwell used - for the first time in the history of theoretical physics - the probability calculus in his model of gas (Maxwell, 1860a, 1860b). From then on, probabilistic considerations played an increasingly important role in Boltzmann's theoretical investigations. In his later work (1872), he analyzed collisions between atoms of gas using the laws of classical mechanics. But then he moved on to probabilistic considerations and introduced a function $H$, 
which he considered, not entirely legitimately, to be the statistical counterpart of Clausius's entropy.

The second law of thermodynamics deals with processes that are irreversible in time, while the laws of mechanics are invariant due to the reversal of the direction of time. This was pointed out by Joseph Loschmidt (1876). As Boltzmann himself wrote in a popular text:

The fundamental equations of mechanics do not in the least change their form if we merely change the algebraic sign of the time variable. All purely mechanical processes can therefore occur equally well in the sense of increasing and decreasing time. But we notice even in ordinary life that future and past $[\ldots]$ are clearly distinguishable.

(Boltzmann, 1974, p. 179)

Boltzmann reacted to Loschmidt's remark peculiarly: later, (2015) he stopped using the laws of mechanics at all. If the motions and collisions of particles were governed by the laws of mechanics, the thermal processes would be reversible. But they are not. Boltzmann does not expressly comment on this, but the fact is that he does not apply any of the laws of mechanics. He only assumes the principle of the conservation of kinetic energy (but he does not use the formula $E_{k}=m v^{2} / 2$ ). Then he tries to found the physics of gases on a purely statistical grounds. He divides kinetic energy of particles into (arbitrarily small) portions $\epsilon$, then - using purely combinatorial methods - he calculates how many ways these portions could be divided among $n$ particles (each of them could have kinetic energy equal to $0, \epsilon, 2 \epsilon, \ldots, p \epsilon$ ). He assumes that the probabilities of all such distributions - microstates - are equal.

What is given in the experiment is a macrostate. Boltzmann states:

[...] it is possible to calculate the state of the equilibrium of heat by finding the probability of the different possible states of the system. The initial state in most cases is bound to be highly improbable and from it the system will always rapidly approach a more probable state until it finally reaches the most probable state, i.e., that of the heat equilibrium.

(Boltzmann, 2015, 1975)

The probability of a macrostate is proportional to the number of microstates realizing it. Microstates are independent of each other (subsequent microstates are not bound by the laws of mechanics). The greatest number of microstates 
corresponds to the situation where the velocity distribution of the particles that make up the gas is Maxwell's distribution. Hence, it follows, for example, that it is much more likely that heat will flow from bodies with higher temperatures to bodies with lower temperatures than vice versa. These are the regularities we observe in experience:

For if we start from the simplest basic assumption as to equal probability, we find for the behavior of aggregates of large numbers of individuals laws that are quite analogous to those that experience shows to hold for the behavior of the material world (Boltzmann, 1974, p. 172).

Boltzmann then showed that some natural phenomena can be explained using only the theory of probability and the principle of conservation of energy. A new research program was thus started. Like any new program, it had a limited range of successful applications, but it was hoped that this range would be expanded. At the turn of the twentieth century, it was already known that a small grain of salt was made of trillions of atoms, and it was possible to speculate whether, for example, the laws of mechanics to which the grain is subject could not be reduced to the laws of the probability calculus.

\section{4}

The young Wittgenstein read Boltzmann's Populäre Schriften (1905). When he studied higher mathematics as part of his engineering degree, he could also read at least excerpts from Boltzmann's (usually very long and chaotic) professional articles or hear about his research program at lectures.

Ludwik Fleck (1935) stated, as a result of research on the history of medicine, that an important source of theoretical novelty in science is misunderstandings between scientists. Wittgenstein cannot be expected to fully understand Boltzmann's research program. Especially that, as Uffink (2017) shows, this program was full of ambiguities, and kept changing from one article to the next. But Wittgenstein could - having missed the role of the principle of conservation of energy - take from Boltzmann the view that pure statistics lie behind the regularities revealed at the macroscopic level.

For the result of purely random events at the microscopic level to be almost necessary regularities at the macroscopic level, the microscopic world must be made up of a great number of elements. In the picture of the world of Tractatus, it would be necessary to have great 
numbers of states of affairs into which reality decomposes and/or a great number of objects that combine into states of affairs. This is equivalent to saying that "ordinary" propositions are truth functions of a great number of elementary propositions and/or that a typical elementary proposition is a combination of a large number of names. When he started working on the book, Wittgenstein remarked:

A proposition like "this chair is brown" seems to say something enormously complicated, for if we wanted to express this proposition in such a way that nobody could raise objections to it on grounds of ambiguity, it would have to be infinitely long.

(Wittgenstein, 1961b, 19.9.1914)

It is not clear from this passage whether there should exist (infinitely) many elementary propositions or whether elementary propositions should be (infinitely) long.

\section{5}

My hypothesis that at the basis of the logical atomism of Tractatus logicophilosophicus there are associations with the program of Boltzmann's statistical physics is confirmed by the presence in the text-in thesis 5.15 and in the comments on it - of the logical theory of probability. The fact that the states of things are independent of each other now takes the form of the statement that "Two elementary propositions give one another the probability 1/2" (5.152). If, on the other hand, we have two propositions $r$ and $s$ which are truth functions of partially the same elementary propositions, they confer some probability on each other. We calculate them by arranging a standard truth table from all elementary propositions occurring in $r$ and $s$, and then in the last two columns we give truth values of $r$ and $s$ for given combinations of truth values of those elementary propositions. For $n$ lines where $r$ is true, $s$ is true in $m$ cases. The ratio $m / n$ determines the probability that the proposition $r$ gives to the proposition $s$. If $m=n$, i.e., $m / n=1$, then $s$ follows logically from $r$.

Moving on to the ontological theses we say that $m / n$ determines the probability of the fact pictured by $s$ if a situation pictured by $r$ is the case. How one could use such a scheme to calculate the probability that the occurrence of a certain fact gives to another fact is not known, as it is not 
known how to perform a complete logical analysis of any non-elementary proposition. There is, however, an analogy with Boltzmann's research program. In Boltzmann's case, all microstates have the same probability. And it follows from Wittgenstein's thesis that only the numbers of rows in the respective truth tables determine the probability that $r$ gives to $s$, that all combinations of truth values of elementary propositions from which a given sentence is built-what Wittgenstein calls the proposition's truth grounds - are equally probable.

The question arises whether there are any analogies, for example, between Wittgenstein's states of affairs and Boltzmann's microstates, or between (possible) facts and macrostates. This question cannot be answered because we know nothing about the structure of elementary propositions except that they are combinations of names. But whether the names are to refer to particulars or to qualities, relations, etc., Wittgenstein does not inform us. There is also nothing about how names intertwine in elementary propositions.

\section{6}

The hypothesis presented in this article about the influence of Boltzmann's research program after 1877 on the early Wittgenstein is speculative. In this respect, it does not differ from the hypotheses formulated by the authors mentioned in $\S 2$, and it is neither more nor less credible. It is not confirmed by any surviving texts. It is supported by the fact that it helps to understand the strange ontological theses of Tractatus mentioned in $\S 1$ : (1) the world divides into states of affairs that are independent of each other; (2) nature is not governed by laws other than the laws of logic, (3) probability is of a logical character. If two facts contain partly the same states of affairs, then the occurrence of one gives some probability of the occurrence of the other.

Boltzmann (1877) treated microstates as independent, not bound by the laws of mechanics. He only used the calculus of probability and the law of conservation of energy (but understood in an abstract way). He concluded that if a physical system is in a certain macrostate, it will have a certain probability of going to a different macrostate.

When speculating about the influence of the research program from (Boltzmann, 1877) on the ontology of Tractatus logico-philosophicus, one 
should, as I have indicated above, take into account Fleck's creative misunderstandings as a source of theoretical novelties.

\section{Bibliography}

Blackmore, J. (1999). Boltzmann and Epistemology. Synthese, 119 (1-2), 157-189.

Blackmore J.T. (1983). Boltzmann and Wittgenstein. In: P. Weingartner, J. Czermak (eds.), Epistemology and Philosophy of Science (pp. 534-537). Vienna: Hölder-Pichler-Tempsky.

Boltzmann, L. (1866). Über die Mechanische Bedeutung des Zweiten Hauptsatzes der Wärmetheorie. Wiener Berichte, 53, 195-220.

Boltzmann, L. (1872). Weitere Studien über das Wärmegleichgewicht unter Gasmolekülen. Wiener Berichte, 66, 275-370.

Boltzmann, L. (1905). Populäre Schriften. Leipzig: Barth.

Boltzmann, L. (1974). On Statistical Mechanics. In: B. McGuinness (ed.) Theoretical Physics and Philosophical Problems (pp. 159-172). Dordrecht: Reidel.

Boltzmann, L. (2015). On the Relationship between the Second Fundamental Theorem of the Mechanical Theory of Heat and Probability Calculations regarding the Conditions for Thermal Equilibrium. Trans. K. Sharp, F. Matschinsky. Entropy, 17, 1971-2009.

Crary, A., Read, R. (eds.) (2000). The New Wittgenstein. London: Routledge.

Fleck, L. (1979). Genesis and Development of a Scientific Fact. Eds. T.J. Trenn, R.K. Merton. Trans. F. Bradley, T.J. Trenn. Chicago: Chicago University Press.

Harré, R. (2001). Wittgenstein: Science and Religion. Philosophy, 76 (296), 211-237.

Loschmidt, J. (1876). Über die Zustand des Wärmegleichgewichtes eines Systems von Körpern mit Rücksicht auf die Schwerkraft, IV. Wiener Berichte, 76, 209-225.

Maxwell, J.C. (1860a). Illustrations of the Dynamical Theory of Gases. Part 1. Philosophical Magazine, 19, 19-32

Maxwell, J.C. (1860b). Illustrations of the Dynamical Theory of Gases. Part 2. Philosophical Magazine, 20, 21-37.

Montibeller, M. (2016). The Duty of Clarity: A Persuasion Effort. Continuity and Physics from Boltzmann to Wittgenstein. Philosophical Investigations, 39 (2), $138-153$. 
Morris, M. (2008). Wittgenstein and the Tractatus. London: Routledge.

Nordmann, A. (2002). Another New Wittgenstein: The Scientific and Engineering Background of the Tractatus. Perspectives on Science, 10 (3), 356-384.

Preston, J.M. (2016). Boltzmann, Hertz, and Wittgenstein. In: H.-J. Glock, J. Hyman (eds.), A Companion to Wittgenstein (pp. 110-123). Chichester: John Wiley.

Proops, I. (2017). Wittgenstein's Logical Atomism. In: E. Zalta (ed.), The Stanford Encyclopedia of Philosophy. Retrieved from: https://plato.stanford.edu/ archives/win2017/entries/wittgenstein-atomism/.

Sluga, H., Stern, D.G. (eds.) (2018). The Cambridge Companion to Wittgenstein. Cambridge: Cambridge University Press.

Stern, D.G. (2002). Sociology of Science, Rule Following and Forms of Life. In: M. Heidelberger, F. Stadler (eds.), History of Philosophy of Science: New Trends and Perspectives, 347-367. Dordrecht: Kluwer.

Sterrett, S.G. (2006). Wittgenstein Flies A Kite: A Story of Models of Wings and Models of the World. New York: Pi Press.

Uffink, J. (2017). Boltzmann's Work in Statistical Physics. In E. Zalta (ed.), The Stanford Encyclopedia of Philosophy. Retrieved from: https://plato.stanford.edu/ archives/spr2017/entries/statphys-Boltzmann/.

Visser, H. (1999). Boltzmann and Wittgenstein or How Pictures Became Linguistic. Synthese, 119 (1-2), 135-156.

Wilson, A.D. (1989). Hertz, Boltzmann and Wittgenstein Reconsidered. Studies in History and Philosophy of Science, 20, 245-263.

Wittgenstein, L. (1961a). Tractatus Logico-Philosophicus. Trans. D.F. Pears, B.F. McGuinness. New York: Humanities Press.

Wittgenstein, L. (1961b). Notebooks 1914-1916. Eds. G.H. von Wright, G.E.M. Anscombe. Oxford: Blackwell.

Wittgenstein, L. (1980). Culture and Value. Ed. G.H. von Wright. Trans. P. Winch. Oxford: Blackwell.

\begin{abstract}
In 1931, when writing about those who had inspired him, Wittgenstein singled out Boltzmann; nobody seems to know why, however. Most commentators have ignored this remark, while a few have tried to guess what the inspiration might have
\end{abstract}


been by searching the popular and philosophical writings of Boltzmann. In this article, I hypothesize that Wittgenstein may have been inspired by Boltzmann's scientific research program from his famous 1877 article. This hypothesis is not confirmed — or rejected — by any surviving documents. But to some extent (considering the role of Fleck's creative misunderstandings) there are two explanations for the origins of the two strange theorems underlying the Tractatus's ontology: (1) each situation can be the case or not the case while everything else remains the same; (2) the facts are not subject to the laws of nature. My hypothesis also makes it understandable why Wittgenstein developed his logical theory of probability. So, let's keep it in mind. 